\title{
Leaf size and specific leaf area of tropical deciduous trees increase with elevation in soil moisture content
}

\begin{abstract}
A functional trait-based approach provides insight into the functional variations between and within tropical deciduous forests across large gradients of soil moisture content (SMC). To test this hypothesis, we selected nine forest fragment sites in the tropical deciduous forest of India, which exhibited significant variations in SMC. At all nine sites, we measured leaf area (LA) and specific leaf area (SLA) of the four deciduous tree species (viz., Buchanania cochinchinensis, Diospyros melanoxylon, Lagerstroemia parviflora and Terminalia tomentosa), which are commonly found in the forest region. We observed significant variations in LA and SLA for the four deciduous tree species across the nine study sites. The inter-species and within species differences were also significant. Moreover, LA and SLA of the four tree species exhibited strong positive linear relationships with SMC across the nine sites. These variations in functional traits were mainly controlled by SMC. We suggest that LA and SLA are important functional traits for detecting the effects of variations in SMC on the physiology and distribution of trees in tropical deciduous forests. Moreover, LA and SLA are the key functional traits which are linked with major ecosystem processes, therefore extensive research on these traits could help in categorizing tree communities for the proper management of tropical deciduous forest ecosystems.
\end{abstract}

Keywords: Tropical deciduous forest; soil moisture content; leaf area; specific leaf area
Volume 2 Issue 4 - 2018

\author{
Chaturvedi RK,' Raghubanshi AS ${ }^{2}$ \\ 'Community Ecology and Conservation Group, Center for \\ Integrative Conservation, Chinese Academy of Sciences, China \\ ${ }^{2}$ Institute of Environment and Sustainable Development, Banaras \\ Hindu University, India
}

\author{
Correspondence: Chaturvedi RK, Community Ecology and \\ Conservation Group, Center for Integrative Conservation, \\ Xishuangbanna Tropical Botanical Garden, Chinese Academy of \\ Sciences, Menglun, Mengla, China, \\ Email ravikantchaturvedil0@gmail.com
}

Received: January 29, 2018 | Published: August 0I, 2018

\section{Introduction}

Tropical deciduous forests experience total annual precipitation ranging from $700-2000 \mathrm{~mm}$, and a mean annual temperature of $25^{\circ} \mathrm{C}$. ${ }^{1}$ The favourable growing period in these forests is very short, during which the soil moisture content (SMC) is adequate for plant growth, while three or more consecutive months, each year are dry with almost no rainfall. ${ }^{2}$ The dominance of drought deciduous trees in the tropical deciduous forests indicates that deciduousness is the most important adaptation to seasonal drought, which results into shedding of leaves and reduction of physiological activities during the unfavourable dry season. ${ }^{2-4}$ Due to spatial and temporal heterogeneity of resources and wide variations in adaptive strategies, tree species of these forests exhibit high inter-specific variation in functional traits..$^{5-7}$ These functional traits have been reported to exhibit direct or indirect association with plant population and ecosystem processes. ${ }^{3}$ According to de Bello et al., ${ }^{8}$ specific ecosystem processes could be influenced by a combination of functional traits, whereas few important key traits could simultaneously affect multiple processes. Therefore, investigation of inter-specific variation in functional traits could explain the patterns and tradeoffs in plant structure and physiological functioning, and the effects of shift in species composition on the functioning of ecosystem.

Functional traits that help plants in acquiring limiting nutrients and water are more important for tropical deciduous species. The pattern of plant water uptake from variable soil depths, which commonly show spatial and temporal differences among various plant functional groups or types, may directly affect soil water dynamics in the growing season. ${ }^{3,9,10}$ Leaf size or leaf area (LA), i.e., one-sided projected leaf surface area, is an important component of plant growth investigations and evapotranspirational measurements. It also has large effect on the rate of transpitation $(\mathrm{E}) .{ }^{11} \mathrm{LA}$ is important parameter for the analysis of tree canopy architecture, since it is useful in determination of leaf area index (LAI). LA is associated with canopy light interception as well as photosynthetic efficiency and plays an important role in carbohydrate metabolism, accumulation of biomass, yield and relative growth rate (RGR). ${ }^{12-14}$ Interspecific differences in LA has been associated with variations in climatic condition, geology, altitude or latitude, particularly in the region where stress due to heat, cold, drought and high-radiation leads to the selection of species with relatively small leaves. Within a particular climatic zone, variations in LA can also be associated with ecological strategy and allometric factors, such as plant height, twig size, architecture, etc., with respect to soil nutrient stress and environmental disturbances, although phylogenetic factors may also play a significant role.

Specific leaf area (SLA) is defined as the light-capturing leaf surface area per unit of dry biomass. It exhibits a trade-off between capture of resources and their conservation, ${ }^{15}$ and has been reported to have significant correlation with net photosynthetic rate, leaf lifespan, relative growth rate, wood specific gravity, and competitive ability. ${ }^{16}$ SLA is considered to vary with leaf phenology. Deciduous species exhibit higher SLA, while evergreen species account lower SLA, which represents a trade-off between shorter leaf longevity with high resource capture capacity and longer leaf longevity with low resource capture capacity. ${ }^{16}$ Variations in SLA are likely significant for the species coexistence in tropical deciduous forests, because greater variation in SLA within a particular community might allow large number of species to partition the available resources across the highly variable environment. ${ }^{1,3,17}$ The investigation of magnitude and patterns of variations in functional traits in tropical 
deciduous forests as compared to other ecosystems is important for understanding the assembly of plant communities in deciduous forests and for understanding pattern of species distributions within as well as between tropical deciduous forest ecosystems, and across dry-wet transitions in the forest region. ${ }^{18}$

Soil water availability has been considered to influence major ecosystem processes in tropical deciduous forest ${ }^{2,4}$ Several studies have observed a considerable impact of SMC on functional traits of deciduous trees. ${ }^{2,3,19,20}$ Among the important functional traits, SLA has been reported to play a significant role in the assembly of plant species across the gradients of light availability and SMC. ${ }^{15}$ The spatio-temporal variations in SMC has been observed to drive habitat associations as well as niche partitioning within tropical forest ecosystems. ${ }^{21}$ However, the variations in functional traits exhibiting shifts in plant distribution patterns in tropical deciduous forests is unknown.Therefore, investigation of variations in LA and SLA of tree species according to differences in SMC could provide a possible insight to distinguish tree communities in tropical deciduous forests. In this study, we have measured LA and SLA of four common deciduous tree species from nine forest fragments exhibiting significant variations in SMC. The study was conducted in the forests of the Vindhyan Highlands located in Sonebhadra district of Uttar Pradesh, India $\left(21^{\circ} 29^{\prime}-25^{\circ} 11^{\prime} \mathrm{N}\right.$ and $\left.78^{\circ} 15^{\prime}-84^{\circ} 15^{\prime} \mathrm{E}\right)$. The area experiences a tropical monsoon climate with three seasons in a year, viz., summer (April-mid June), rainy (mid June-September), and winter (November-February). The months of March and October constitute transition periods, respectively, between winter and summer and between rainy and winter seasons. The maximum monthly temperature varies from $20^{\circ} \mathrm{C}$ in January to $46^{\circ} \mathrm{C}$ in June, and the mean minimum monthly temperature reaches $12^{\circ} \mathrm{C}$ in January and $31{ }^{\circ} \mathrm{C}$ in May. According to data collected from the meteorological stations of the state forest department for 1980-2010, the mean annual rainfall ranges from 865 to $1,196 \mathrm{~mm}^{22}$ About $85 \%$ of the annual rainfall occurs during the monsoon (rainy) season from the southwest monsoon and the remaining from the few showers in December and in May-June. There is an extended dry period of about 9 months (October-mid June) in the annual cycle. ${ }^{6}$ The monthly rainfall varies from $6 \mathrm{~mm}$ in April to $334 \mathrm{~mm}$ in August. ${ }^{23}$ Soils of the study area are residual ultisols, sandy-loam in texture, reddish to dark gray in color, and extremely poor in nutrients. ${ }^{7}$ The forest region exhibits patchiness in the species composition due to small variations in the environmental factors. ${ }^{17}$ Species composition, distribution and diversity, ${ }^{24}$ and seasonal growth. ${ }^{18-27}$ of woody species are highly influenced by the SMC. The density dbh distributions in the forest region exhibited a low dbh-biased structure, where the average densities of seedlings, saplings, and adults per ha were 9,261, 799, and 297, respectively. ${ }^{24}$

We selected nine forest fragment sites in the Vindhyan Highlands, which exhibited significant variations in SMC (Table 1). The minimum distance between the two sites was at least two kms. We measured LA and SLA on the four deciduous tree species (viz., Buchanania cochinchinensis, Diospyros melanoxylon, Lagerstroemia parviflora and Terminalia tomentosa), which are commonly found in the forest region. ${ }^{24}$ At each selected site, we randomly marked three individuals $(>10 \mathrm{~cm}$ DBH) from each of the four tree species $(9 \times 3 \times 4=108$ trees). For measurement of LA and SLA, 30 mature and healthy, sun facing leaf samples were collected in the month of September from each selected tree. During leaf collection we also measured SMC under the canopy of each tree, at a distance of $1 \mathrm{~m}$ from the trunk, using a theta probe instrument (type ML 1, Delta-T
Devices, Cambridge, UK). LA and SLA were measured following the protocol given in Chaturvedi [6]. The data was analysed in R (R Foundation for Statistical Computing, Vienna, AT), package (lme4). Among the four tree species, across the nine sites the data showed highest SMC and LA for Terminalia tomentosa, whereas lowest SMC and LA for Diospyros melanoxylon (Figure 1). SLA was greatest in Lagerstroemia parviflora and lowest in Buchanania cochinchinensis. Results exhibited significant site-wise and species-wise differences for SMC, LA and SLA (Table 1). The two-way interaction of site and species also indicated significant differences (Table 1). We recorded significant positive correlation of SMC with LA and SLA for the four tree species across the nine sites (Table 2). Similarly, the relationship of LA with SLA was also positively significant for the four tree species across the nine sites (Table 2). We also observed strong linear relationship between LA and SMC (Figure 2a), as well as between SLA and SMC (Figure 2) for all four tree species across the nine sites. On the basis of our findings, we suggest that LA and SLA are important functional traits for detecting the effects of variations in SMC on the physiology and distribution of trees in tropical deciduous forests. LA and SLA are the key functional traits which are linked with major ecosystem processes, and extensive research on these traits could help in categorizing tree communities for proper management of the tropical deciduous forest ecosystems.
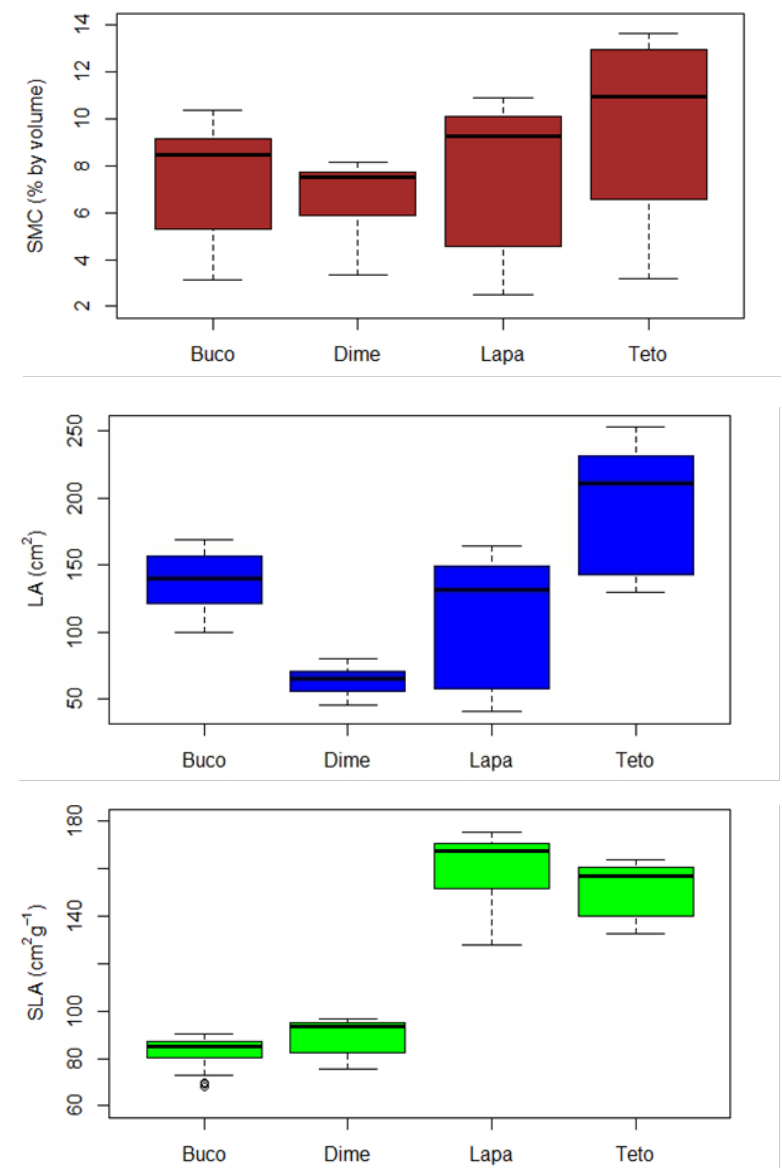

Figure 1 Boxplot of difference between (A) soil moisture content (SMC) below the canopy, (B) leaf area (LA) and (C) specific leaf area (SLA) of the four deciduous tree species. Boxplot shows median and interquartile range, whiskers indicate the range. Buco, Buchanania cochinchinensis; Dime, Diospyros melanoxylon; Lapa, Lagerstroemia parviflora; Teto, Terminalia tomentosa. 


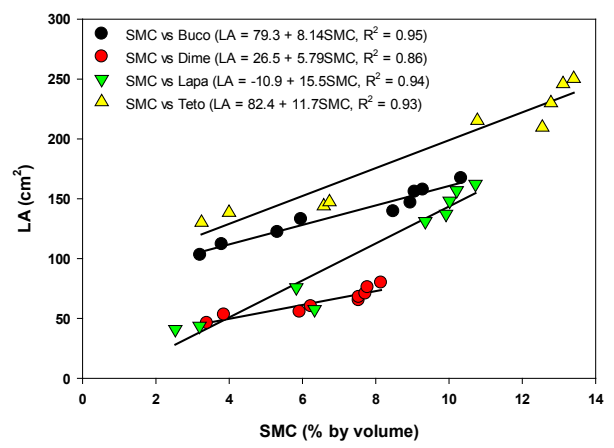

(A)

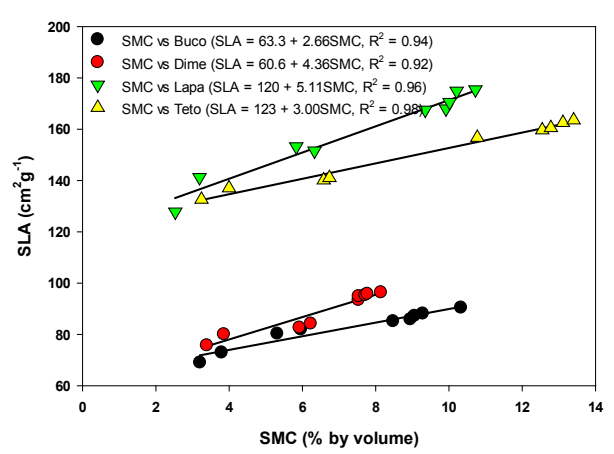

(B)

Figure 2 Linear relationships between (A) leaf area (LA) and soil moisture content (SMC), and between (B) specific leaf area (SLA) and SMC of the four deciduous tree species.

Table 1 Summary of ANOVA on soil moisture content (SMC) below the tree canopy, leaf area (LA), and specific leaf area (SLA) of the four important tree species of the tropical deciduous forest. Residual $\mathrm{df}=72 .{ }^{* * * \mathrm{P}}<0.001$

\begin{tabular}{lllll}
\hline Factor & df & SMC & LA & SLA \\
\hline Site & 8 & $5854^{* * *}$ & $2659^{* * *}$ & $127000^{* * *}$ \\
Species & 3 & $2195^{* * *}$ & $15610^{* * *}$ & $3864000 * * *$ \\
Site $\times$ Species & 24 & $190.9 * * *$ & $261.5^{* * *}$ & $5909 * * *$ \\
\hline
\end{tabular}

Table 2 Pearson's correlation among soil moisture content (SMC) below the tree canopy, leaf area (LA), and specific leaf area (SLA) of the four important tree species of the tropical deciduous forest. $\mathrm{n}=27$. ${ }^{* * * \mathrm{P}<0.001}$

\begin{tabular}{|c|c|c|}
\hline & SMC & LA \\
\hline \multicolumn{3}{|c|}{ Buchanania cochinchinensis } \\
\hline LA & $0.971 * * *$ & \\
\hline SLA & $0.967 * * *$ & $0.966 * * *$ \\
\hline \multicolumn{3}{|c|}{ Diospyros melanoxylon } \\
\hline LA & $0.924^{* * *}$ & \\
\hline SLA & $0.961^{* * *}$ & $0.952 * * *$ \\
\hline \multicolumn{3}{|c|}{ Lagerstroemia parviflora } \\
\hline LA & $0.966 * * *$ & \\
\hline
\end{tabular}

\begin{tabular}{|c|c|c|}
\hline SLA & $0.981 * * *$ & $0.953 * * *$ \\
\hline & SMC & LA \\
\hline \multicolumn{3}{|c|}{ Terminalia tomentosa } \\
\hline LA & $0.963 * * *$ & \\
\hline SLA & $0.992 * * *$ & $0.983 * * *$ \\
\hline
\end{tabular}

\section{Conclusion}

A functional trait-based approach provides insight into the functional variations between and within tropical deciduous forests across large gradients of SMC. We observed significant differences for LA and SLA of the four important deciduous tree species across the nine study sites in a gradient of SMC. The inter-species and within species differences were also significant. LA and SLA of the four tree species exhibited strong positive linear relationships with SMC across the nine sites. These variations in functional traits were mainly controlled by SMC. We suggest that LA and SLA are important functional traits for detecting effects of variations in SMC on the physiology and distribution of trees in tropical deciduous forests. LA and SLA are the key functional traits which are linked with major ecosystem processes, and extensive research on these traits could help in categorizing tree communities for proper management of the tropical deciduous forest ecosystems.

\section{Acknowledgements}

RKC thanks Council of Scientific and Industrial Research, India (award no. 09/13(452)/2012-EMR-I) and Natural Science Foundation of China (NSFC), Chinese Academy of Science, China (grant No. 31750110466) for financial support.

\section{Conflict of interests}

The author declares there is no conflict of interest.

\section{References}

1. Singh JS, Chaturvedi RK. Tropical Dry Deciduous Forest: Research Trends and Emerging Features. Singapore: Springer Nature Singapore Pte Ltd. 2018.

2. Chaturvedi RK, Raghubanshi AS. Soil water availability influences major ecosystem processes in tropical dry forest. International Journal of Hydrology. 2018;2(1):14-15.

3. Chaturvedi RK, Raghubanshi AS, Singh JS. Plant functional traits with particular reference to dry deciduous forests: a review. Journal of Biosciences. 2011;36(5):963-981.

4. Chaturvedi RK, Raghubanshi AS. Leaf life-span dynamics of woody species in tropical dry forests of India. Tropical Plant Research. 2016;3(1):199-212.

5. Kooyman RM, Westoby M. Costs of height gain in rainforest saplings: main-stem scaling, functional traits and strategy variation across 75 species. Annals of Botany. 2009;104:987-993.

6. Chaturvedi RK. Plant functional traits in dry deciduous forests of India. $\mathrm{PhD}$ thesis, Department of Botany, Banaras Hindu University, Varanasi, India. 2010.

7. Chaturvedi RK, Raghubanshi AS. Plant Functional Traits in a Tropical Deciduous Forest: An analysis. Lambert Academic Publishing GmbH \& Co. KG, Berlin, Germany. 2011.

8. De Bello F, Lavorel S, Díaz S, et al. Towards an assessment of multiple ecosystem processes and services via functional traits. Biodiversity and 
Conservation. 2010;19(10):2873-2893.

9. Ryel RJ, Ivans CY, Peek MS, et al. Functional differences in soil water pools: a new perspective on plant water use in water-limited ecosystems. Progress in Botany. 2008;69:397-422.

10. Schwinning S. The ecohydrology of roots in rocks. Ecohydrology. 2010;3:238-245.

11. Enoch HZ, Hurd RG. The effect of elevated $\mathrm{CO}_{2}$ concentrations in the atmosphere on plant transpiration and water use efficiency. A study with potted carnation plants. International Journal of Biometeorology. 1979;23(4):343-351.

12. Leith JH, Reynolds JP, Rogers HH. Estimation of leaf area of soybeans grown under elevated carbon dioxide levels. Field Crops Research. 1986;13:193-203.

13. Williams LE. Growth of 'Thompson Seedless' grapevines: I. Leaf area development and dry weight distribution. Journal of American Society for Horticultural Science. 1987;112:325-330.

14. Centritto $\mathrm{M}$, Loreto $\mathrm{R}$, Massacci A, et al. Improved growth and water use efficiency of cherry saplings under reduced light intensity. Ecological Research. 2000;15(4):385-392.

15. Poorter L. Leaf traits show different relationships with shade tolerance in moist versus dry tropical forests. New Phytologist. 2009;181(4):890900 .

16. Reich PB, Walters MB, Ellsworth DS. From tropics to tundra: global convergence in plant functioning. Proceedings of the National Academy of Sciences, USA. 1997;94(25):13730-13734.

17. Chaturvedi RK, Raghubanshi AS, Singh JS. Effect of small scale variations in environmental factors on the distribution of woody species in tropical deciduous forests of Vindhyan Highlands, India. Journal of Botany. 2011:1-10.

18. Chaturvedi RK, Raghubanshi AS, Singh JS. Leaf attributes and tree growth in a tropical dry forest. Journal of Vegetation
Science. 2011;22(5):917-931.

19. Chaturvedi RK, Raghubanshi AS, Singh JS. Growth of tree seedlings in a dry tropical forest in relation to soil moisture and leaf traits. Journal of Plant Ecology. 2013;6(2):158-170.

20. Chaturvedi RK, Raghubanshi AS, Singh JS. Relative effects of different leaf attributes on sapling growth in tropical dry forest. Journal of Plant Ecology. 2014;7(6):544-558.

21. Segura G, Balvanera P, Durán E, et al. Tree community structure and stem mortality along a water availability gradient in a Mexican tropical dry forest. Plant Ecology. 2003;169(2):259-271.

22. Chaturvedi RK, Raghubanshi AS, Singh JS. Carbon density and accumulation in woody species of tropical dry forest in India. Forest Ecology and Management. 2011;262(8):1576-1588.

23. Chaturvedi RK, Raghubanshi AS, Singh JS. Effect of grazing and harvesting on diversity, recruitment and carbon accumulation of juvenile trees in tropical dry forests. Forest Ecology and Management. 2012;284(2012):152-162.

24. Chaturvedi RK, Raghubanshi AS. Species Composition, Distribution and Diversity of Woody Species in tropical dry forest of India. Journal of Sustainable Forestry. 2014;33(8):729-756.

25. Chaturvedi RK, Raghubanshi AS. Assessment of carbon density and accumulation in mono-and multi-specific stands in Teak and Sal forests of a tropical dry region in India. Forest Ecology and Management. 2015;339:11-21.

26. Chaturvedi RK, Raghubanshi AS, Singh JS. Sapling harvest: A predominant factor affecting future composition of tropical dry forests. Forest Ecology and Management. 2017;384:221-235.

27. Chaturvedi RK, Raghubanshi AS, Tomlinson KW, et al. Impacts of human disturbance in tropical dry forests increase with soil moisture stress. Journal of Vegetation Science. 2017;28(5):997-1007. 